\title{
Le rire cruel de Joseph Danan
}

\section{Bernadette Bost}

\section{OpenEdition}

Journals

Édition électronique

URL : http://journals.openedition.org/recherchestravaux/158

DOI : 10.4000/recherchestravaux.158

ISSN : 1969-6434

\section{Éditeur}

UGA Éditions/Université Grenoble Alpes

\section{Édition imprimée}

Date de publication : 15 octobre 2006

Pagination : 111-112

ISBN : 978-2-84310-099-4

ISSN : 0151-1874

\section{Référence électronique}

Bernadette Bost, «Le rire cruel de Joseph Danan », Recherches \& Travaux [En ligne], 69 | 2006, mis en ligne le 25 novembre 2008, consulté le 08 septembre 2020. URL : http://journals.openedition.org/ recherchestravaux/158; DOI : https://doi.org/10.4000/recherchestravaux.158 


\section{Le rire cruel de Joseph Danan}

L'humour et la cruauté se mêlent étrangement dans le théâtre de Joseph Danan, en particulier dans les deux pièces pour jeune public que sont Les Aventures d'Auren le petit serial killer ${ }^{\mathrm{I}}$ et Jojo le récidiviste ${ }^{2}$. On y tue allègrement et sans répit, et pas seulement "le temps" contre lequel tentent de se mobiliser les enfants. Auren a beau apparaître comme «le plus gentil petit garçon de la terre", il se rêve tueur, petit frère de Roberto Zucco quand il confie à une gamine, à l'instar du héros de Koltès, son nom secret d'assassin sans raison. Le spectacle d'une fourmilière lui donne envie d'une bombe atomique et son fantasme de destruction le fait bientôt passer d'Hiroshima au World Trade Center, "les deux tours d'un coup». Est-ce vraiment cruel, comme le suggère son amie, de jouer ainsi mentalement les exterminateurs? "C'est comme un rêve», constate Auren, et sa vie tout entière - La Vie? - se déroule ainsi dans un espace intermédiaire entre réalité sordide et vagabondages d'imagination. Auren habite l'entre-deux, en terme d'espace comme de désir. Parce que le monde est foncièrement insupportable, il va et vient entre évasion et régression, blottissement dans une petite enfance à jamais préservée, et envol à tire-d'aile vers des mondes plus exaltants. Autour de lui, la société prodigue ses périls. Les trois copains d'Auren connaisssent la précarité des enfants de sans-papier, partagent les angoisses de pères qui s'épuisent à repousser la menace d'arrestation, de tabassage, d'emprisonnement, de renvoi au pays d'origine. Auren est préservé de ce malheur-là puisque son père à lui est "passé par la fenêtre» et qu'on ne l'a "plus jamais revu». Mais tous les hommes qui s'interposent entre lui et son rêve sont par lui liquidés, après transformation en animaux de bande dessinée. Le comique de l'affaire se glisse dans les jeux de langage, comme les contrepèteries involontaires d'un hibou bafouilleur, et l'humour

I. Arles, Actes Sud - Papiers, «Heyoka jeunesse», 2003.

2. Pièce de 2005. À parâtre aux éditions Actes Sud - Papiers en 2007, dans la collection «Heyoka jeunesse». 
trouve sa place dans l'écart entre les violences revendiquées et le charme d'un conte initiatique où les misères du vrai monde sont conjurées.

Avec Jojo le récidiviste, on pourrait croire qu'on assiste à un remake des Malheurs de Sophie au masculin, tant le héros, affreux jojo, collectionne les bêtises: il renverse l'eau des fleurs, cisaille les tiges, massacre les fruits, il salit, souille et brûle tout ce qu'on peut salir, souiller, brûler. Innocentes pratiques propres à désamorcer les potentielles agressions meurtrières? En fait, on assiste à un pas de deux bien réglé entre l'enfant provocateur et une mère à la main leste. Les distributions de gifles rythment ce qu'on ose à peine dire «le drame ", drame d'une vie bien quotidienne, avec son cortège d'accidents et de maladies, de faits divers et d'événements médiatiques, de sauvetages héroïques et d'interrogatoires musclés. Jojo n'a pas de suite dans ses idées destructrices, contrairement à Auren, mais il se plait à parodier les simulacres d'existences exposés par le cinéma ou les séries télévisées. On pourrait dire qu'il répète consciencieusement les situations dans lesquelles il lui faudra un jour s'installer. Mais comme l'ordinaire peut manquer par trop de saveur, il s'offre de l'insolite, joue aux gangsters et aux Indiens, expérimente la vie sauvage en mastiquant une page de livre, en faisant griller une pantoufle, ou en tirant, avec la carabine de son père, sur un canari. On pourrait se croire loin de Roberto Zucco, mais le héros mythique de Koltès n'est pas si loin. À la fin, c'est son apothéose (ou sa chute) que parodie Jojo allant à la rencontre du soleil. Décidément, tout enfant porte en lui un poète et un tueur, et la réussite de Joseph Danan, entre comédie et tragédie, est de les faire poétiquement cohabiter.

Dans le texte suivant, Joseph Danan confie à Recherches \& Travaux quelques réflexions sur la place du comique et de l'humour dans ses pièces. Ce dramaturge, né en I95I, est l'auteur de plus de trente pièces longues ou brèves, publiées notamment aux Éditions Lansman, Médianes, ou diffusées en tapuscrits par Théâtre ouvert. Universitaire, il est également l'auteur d'essais sur le théâtre comme Le Théâtre de la pensée (Médianes, 1995). 